\title{
Bacillus-Based Probiotic Treatment Modified Bacteriobiome Diversity in Duck Feces
}

\author{
Natalia B. Naumova ${ }^{1, *}$, Tatiana Y. Alikina ${ }^{1}$, Natalia S. Zolotova ${ }^{2}$, Alexey V. Konev ${ }^{2}$, Valentina I. Pleshakova ${ }^{2}$, \\ Nadezhda A. Lescheva ${ }^{2}$ and Marsel R. Kabilov ${ }^{1}$ (D) \\ 1 Institute of Chemical Biology and Fundamental Medicine, Siberian Branch of the Russian Academy \\ of Sciences, Lavrentieva 8, 630090 Novosibirsk, Russia; alikina@niboch.nsc.ru (T.Y.A.); \\ kabilov@niboch.nsc.ru (M.R.K.) \\ 2 The Faculty of Veterinary Medicine, Stolypin Omsk State Agrarian University, Institutskaya pl. 1, \\ 644008 Omsk, Russia; ns.zolotova@omgau.org (N.S.Z.); av.konev@omgau.org (A.V.K.); \\ vi.pleshakova@omgau.org (V.I.P.); lescheva@list.ru (N.A.L.) \\ * Correspondence: naumova@niboch.nsc.ru
}

Citation: Naumova, N.B.; Alikina, T.Y.; Zolotova, N.S.; Konev, A.V.; Pleshakova, V.I.; Lescheva, N.A.; Kabilov, M.R. Bacillus-Based Probiotic Treatment Modified Bacteriobiome Diversity in Duck Feces. Agriculture 2021, 11, 406. https://doi.org/ 10.3390 /agriculture 11050406

Academic Editor: István Komlósi

Received: 7 April 2021

Accepted: 26 April 2021

Published: 1 May 2021

Publisher's Note: MDPI stays neutral with regard to jurisdictional claims in published maps and institutional affiliations.

Copyright: (c) 2021 by the authors. Licensee MDPI, Basel, Switzerland. This article is an open access article distributed under the terms and conditions of the Creative Commons Attribution (CC BY) license (https:/ / creativecommons.org/licenses/by/ $4.0 /)$.

\begin{abstract}
The intestinal health of poultry is of great importance for birds' growth and development; probiotics-driven shifts in gut microbiome can exert considerable indirect effect on birds' welfare and production performance. The information about gut microbiota of ducks is scarce; by using high throughput metagenomic sequencing with Illumina Miseq we examined fecal bacterial diversity of Peking ducks grown on conventional and Bacillus-probiotic-enriched feed. The probiotic supplementation drastically decreased the presence of the opportunistic pathogen Escherichia/Shigella, which was the major and sole common dominant in all samples. Seventy other bacterial species in the ducks' fecal assemblages were found to have probiotic-related differences, which were interpreted as beneficial for ducks' health as was confirmed by the increased production performance of the probiotic-fed ducks. Bacterial $\alpha$-biodiversity indices increased in the probiotic-fed group. The presented inventory of the duck fecal bacteriobiome can be very useful for the global meta-analysis of similar data in order to gain a better insight into bacterial functioning and interactions with other gut microbiota to improve poultry health, welfare and production performance.
\end{abstract}

Keywords: 16S rRNA gene; amplicon sequencing; ducks; probiotic; gut microbiome

\section{Introduction}

Over 21 million ducks are raised for human consumption each year in the Russian Federation [1], yet so far no research has been conducted on the gut microbiome of the Pekin duck breed, maintained in the country. The intestinal health of poultry is of great importance for birds' welfare and hence their production performance, food safety and environmental consequences [2]. Industrial poultry production still relies on antibiotics as growth promoters, although probiotics nowadays are becoming an increasingly indispensable pharmacological component for production of high quality food [3]. Probiotic preparations can be based on different microorganisms, including the spore-producing ones like Bacillus [4,5], which are Gram-positive, aerobic, spore-forming bacteria ubiquitous in the environment. Importantly, they have high stability under adverse environmental conditions, which is indispensable for probiotic cells to survive processing and storage of feed, its passage through the gastrointestinal tract and subsequent chemical digestion processes. The antagonistic effect of such probiotics on the pathogenic gut microflora of humans and animals has been known since long ago [6]. However, most research about the effect of dietary administration of probiotic Bacillus strains on growth performance has been conducted in chicken, mouse, and pig [7-10], and yet only recently it was experimentally shown that certain strains of $B$. subtilis can provide beneficial effects on the growth of young broiler chickens and have the potential to replace antibiotic growth promoters [11] or 
improve egg quality [12]. Similar studies on ducks have been fewer $[13,14]$, and we failed to find reports on gut microbiome research using probiotic Bacillus strains for Pekin ducks.

Knowledge of the microbiome profiles in regional agricultural populations could help in drawing a global picture of duck gut microbiota, leading to a better insight into the regional effects of production technologies such as the use of probiotics, prebiotics, synbiotics, enzymes and antibiotics. As there is still a gap in knowledge concerning the effectiveness of probiotic supplementation in shaping gastrointestinal taxonomic profiles in ducks, the objective of the study was to examine composition and structure of ducks' gut bacterial assemblages by estimating diversity of phylogenetically significant fragments of $16 \mathrm{~S}$ rRNA genes from the feces of ducks grown on conventional and probiotic-enriched feed by using high throughput metagenomic sequencing.

\section{Materials and Methods}

\subsection{Duck Breed and Experimental Design}

All experimental procedures involving ducks met the guidelines approved by the institutional animal care and use committee and were performed in accordance with the Russian National Law concerning the care of animals for research purposes, as well as in compliance with the European Commission Directive 2010/63/EU on the protection of animals used for scientific purposes [15]. Ducks Anas platyrhynchos of the Peking breed Agidel variety were raised and grown at a poultry farm in the Omsk region, Russia, and female ducks were used in the study. Until 10 days of age the ducklings were kept in stainless steel cages at $+28-30{ }^{\circ} \mathrm{C}$ and $65-70 \%$ relative humidity on a small-mesh-flooring; after that they were put into a bigger house where they could freely roam on a deep pineshaving-based litter at $+25^{\circ} \mathrm{C}$. Then, the 30 - $\mathrm{d}$-old birds were placed into the premises with similar deep litter, air temperature of $+14-20^{\circ} \mathrm{C}$, drinking water ad libitum and access to artificial ponds. From the first day of life to three weeks of age, the ducks were fed ad libitum with a starter diet (wheat, soya beans, oil free sunflower seed, sunflower seed cake, fish flour, methionine, threonine, lysine, sodium chloride, premix), providing $3100 \mathrm{kcal} / \mathrm{kg}$ of feed and $23 \%$ of crude protein. Then, from four to five weeks of age, the birds were fed with a grower diet with threonine substituted with cysteine and providing $3150 \mathrm{kcal} / \mathrm{kg}$ of feed and $21 \%$ of crude protein. Additionally, from 6 weeks of age until the end of the performance the ducks were fed with a similar diet but providing $3200 \mathrm{kcal} / \mathrm{kg}$ of feed and $20 \%$ of crude protein.

The ducks were assembled in two groups of sixteen birds in each. One group received conventional feed as described above supplemented with a probiotic (probiotic-fed) during the entire growth period of $60 \mathrm{~d}$ as per manufacturer's instructions, i.e., $0.4 \mathrm{~kg} / \mathrm{t}$ during the first $15 \mathrm{~d}$ followed by $1.0 \mathrm{~kg} / \mathrm{t}$ till the end of the growth. The other group received only conventional feed (control).

The commercially distributed probiotic preparation Olin ${ }^{\circledR}$, produced for Probiotic-Plus LLC (Russia) [16], was used in the study. According to the manufacturer, the preparation contains dried biomass of antagonistically active strains of Bacillus subtilis and Bacillus licheniformis, registered in the Russian Collection of Industrial Microorganisms under accession numbers 10172 and 10135, respectively, with plate counts of at least $2 \times 10^{9} \mathrm{CFU}$ per $1 \mathrm{~g}$ of the preparation [17].

\subsection{Sample Collection}

At sixty days of age, all birds were weighed, and five apparently healthy ducks were selected at random from each group, caught, not fed for $8 \mathrm{~h}$, but could drink ad libitum, and then euthanized by cervical dislocation in compliance with the European Commission Directive 2010/63/EU on the protection of animals used for scientific purposes [15]. Within two hours the recta were opened using sterile scissors, and the contents were collected into sterile vials and frozen at $-196{ }^{\circ} \mathrm{C}$. In the laboratory the samples were stored at $-80^{\circ} \mathrm{C}$ prior to the DNA extraction. 


\subsection{Extraction of Total Nucleic Acid from Feces}

Total DNA was extracted from $250 \mathrm{mg}$ of feces using the DNeasy Powersoil Kit (Qiagen, Germany) as per the manufacturer's instructions [18] to lyse microbial cells and obtain high-quality DNA solutions free from PCR inhibitors. The bead-beating was performed using a TissueLyser II (Qiagen, Germany), for $10 \mathrm{~min}$ at $30 \mathrm{~Hz}$. No further purification of the DNA was needed. The quality of the DNA was assessed using agarose gel electrophoresis.

\section{4. $16 S$ rRNA Gene Amplification and Sequencing}

The 16S DNA region was amplified with the primer pair F343 (5'-TACGGRAGGCAG CAG-3') and R803 (5'-CTACCAGGGTATCTAATCC-3') combined with Illumina adapter sequences [19]. PCR amplification was performed as described earlier [20]. A total of $200 \mathrm{ng}$ PCR product from each sample was pooled together and purified through a MinElute Gel Extraction Kit (Qiagen, Germany). The obtained libraries were sequenced with $2 \times 300 \mathrm{bp}$ paired-ends reagents on MiSeq (Illumina, San Diego, CA, USA) in the SB RAS Genomics Core Facility (ICBFM SB RAS, Novosibirsk, Russia). The read data reported in this study were submitted to the GenBank under the study accession PRJNA523560.

\subsection{Bioinformatic and Statistical Analyses}

Raw sequences were analyzed with the UPARSE pipeline [21] using Usearch v11.0. The UPARSE pipeline included merging of paired reads; read quality filtering; length trimming; merging of identical reads (dereplication); discarding singleton reads; removing chimeras and operational taxonomic unit (OTU) clustering using the UPARSE-OTU algorithm. The OTU sequences were assigned a taxonomy using the SINTAX [22] and 16S RDP training set v.16 [23].

Taxonomic structure of thus obtained sequence assemblages, i.e., a collection of different species at one site at one time [24], was estimated by the ratio of the number of taxon-specific sequence reads to the total number of sequence reads, i.e., by the relative abundance of taxa, expressed as a percentage.

Statistical analyses of the data were perfumed using Statistica v.13.3 software (Statsoft, Tulsa, OK, USA). Comparison of relative abundances of different bacterial taxa in fecal samples of the control and probiotic-fed group was carried out using the Mann-Whitney nonparametric test, whereas comparison of ducks' production characteristics ANOVA and Fisher's least significant difference test were carried out. The rarefaction curves were obtained using iNEXT 2.0.15 in R-package [25] and biodiversity indices calculated with the help of PAST 2.17 software [26].

\section{Results}

\subsection{Taxonomic Richness and Structure of Duck Fecal Bacterial Assemblages}

After $16 \mathrm{~S}$ gene amplicon sequencing, quality filtering and chimera removal a total of 666,588 high-quality DNA sequences were obtained from feces of the 10 ducks. Highquality reads were clustered using $>97 \%$ sequence identity into 568 bacterial operational taxonomic units (OTUs). The obtained sets of sequences for each sample were analyzed by plotting the number of OTUs against the total number of sequence reads (Figure 1). The resulting rarefaction curves demonstrated sufficient out coverage to describe the bacterial composition and compare assemblages of different groups [27]. 


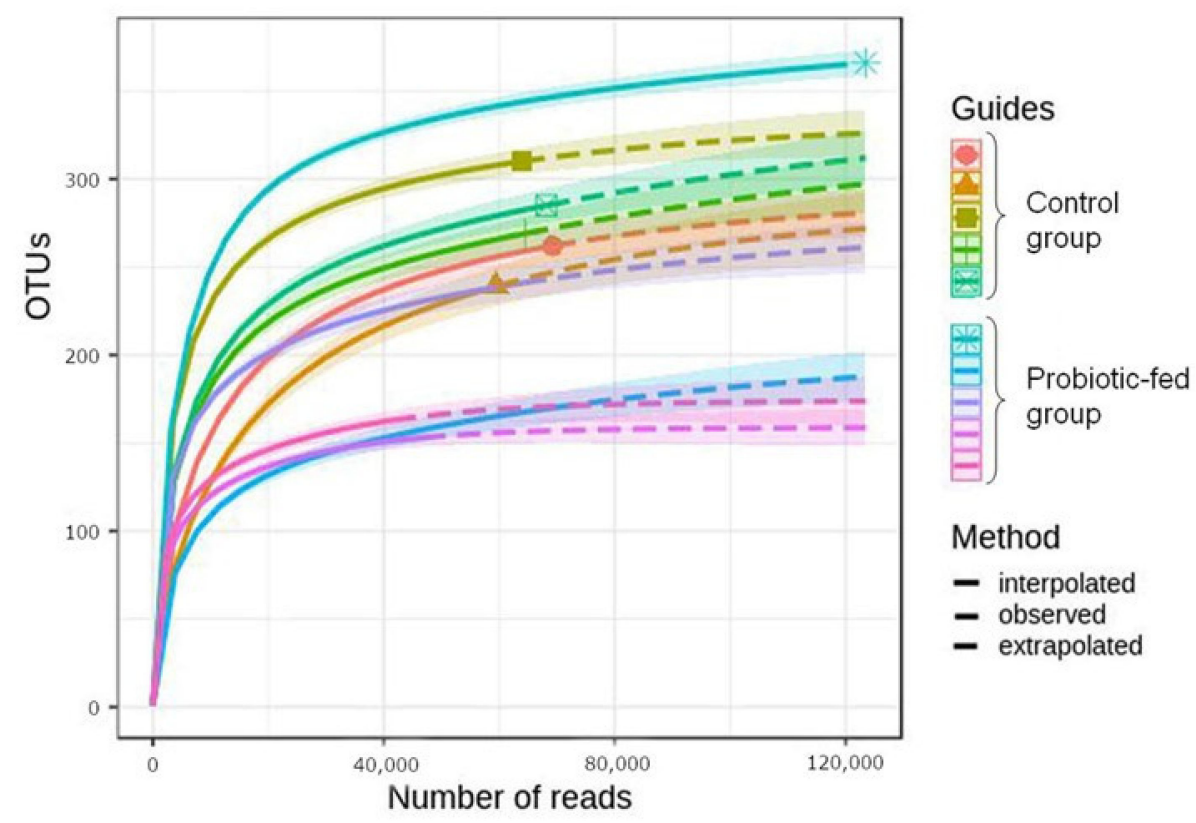

Figure 1. Rarefaction curves for the OTU number in fecal bacterial assemblages of the ducks.

The total number of different-level taxa identified in the study is shown in Table 1 . The mooutOTU-rich phyla were Proteobacteria (147 OTUs, or $26 \%$ of the total number of identified OTUs) and Firmicutes with (134 OTUs, or 24\%), followed by Actinobacteria (131 OTUs, or $23 \%$ ) and Bacteroideteout 25 OTU, or $4 \%$ ). Taxonomic richness in the studied samples was found to drastically decrease if only the dominant members, i.e., the ones contributing at least $1 \%$ into the total number of sequence reads, of the bacterial assemblages, were taken into account (Table 1).

Table 1. Taxonomic richness of fecal bacterial assemblages of ducks.

\begin{tabular}{ccccc}
\hline & & \multicolumn{3}{c}{ Taxonomic Attribution } \\
\cline { 2 - 5 } Taxon Level & \multirow{2}{*}{ All OTUs } & & Dominant ${ }^{\text {a }}$ OTUs \\
\cline { 3 - 5 } & & Both Groups & Control Group & Probiotic-Fed Group \\
\hline Phylum & 15 & 4 & 3 & 3 \\
Class & 36 & 6 & 4 & 6 \\
Order & 63 & 9 & 4 & 6 \\
Family & 137 & 12 & 5 & 12 \\
Genus & 251 & 13 & 5 & 13 \\
OTU & 567 & 6 & 5 \\
\hline
\end{tabular}

a OTUs were considered dominant if their relative abundance was more than $1 \%$.

Two bacterial phyla-Firmicutes and Proteobacteria-collectively accounted for more than $90 \%$ of the total sequence reads in fecal assemblages (Figure $2 \mathrm{a}$ ). The overwhelming majority of sequences represented three classes (Figure 2b), three orders (Figure 2c), just six families (Figure 2d) and six genera (Escherichia/Shigella, Terrisporobacter, Streptococcus, Enterococcus, Romboutsia and an unclassified representative of Clostridiaceae, Figure 3). The commercial probiotic preparation, fed to the ducks in the study, was found to contain 54 OTUs, with one OTU (Bacillus sp.) accounting for $58 \%$ of the total number of sequence reads, detected in the preparation. Other dominant components of the probiotic preparation were Pseudomonas spp. (three OTUs), Comamonas sp. (one OTU) and unclassified Enterobacteriaceae (two OTUs). These bacteria were practically absent in fecal bacteriobiomes of both groups. Overall Bacillus class was represented by seven OTUs in fecal assemblages of ducks (Figure 2b), collectively accounting for a tiny portion of the total 
number of sequence reads $(0.015 \%$ and $0.002 \%$ in the control and probiotic-fed groups, respectively).

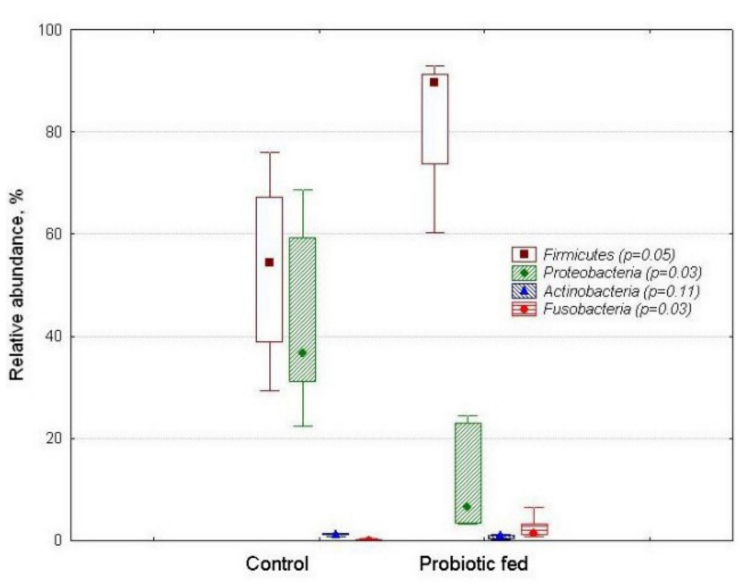

(a)

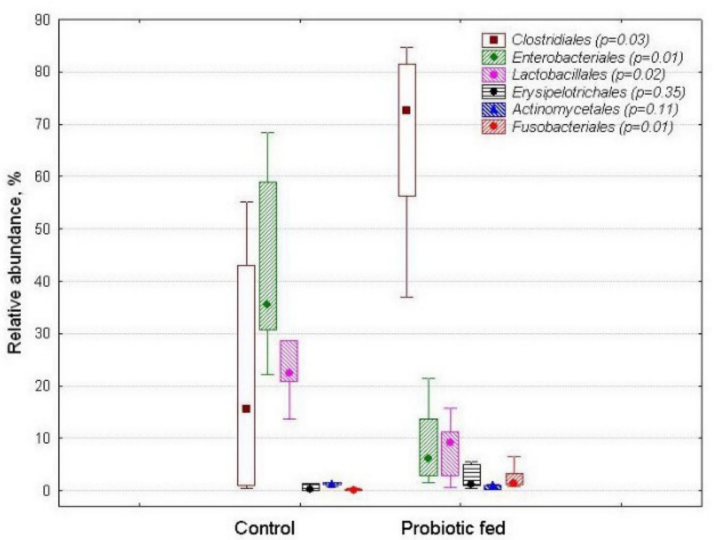

(c)

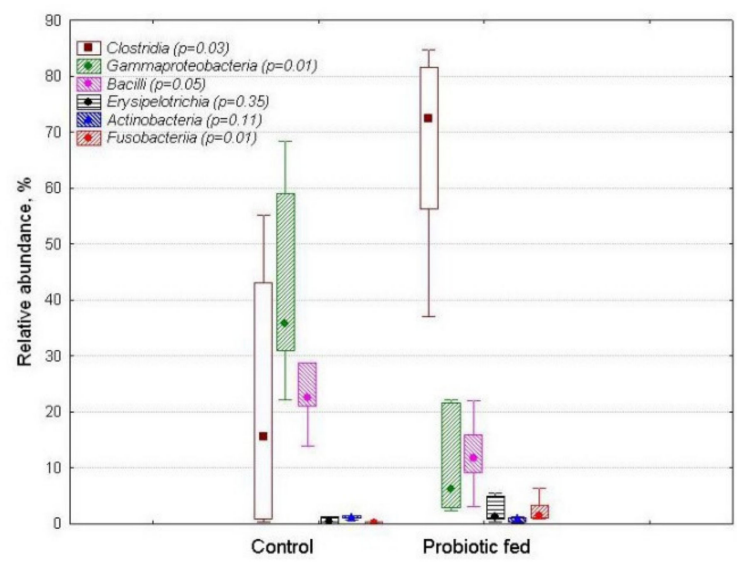

(b)

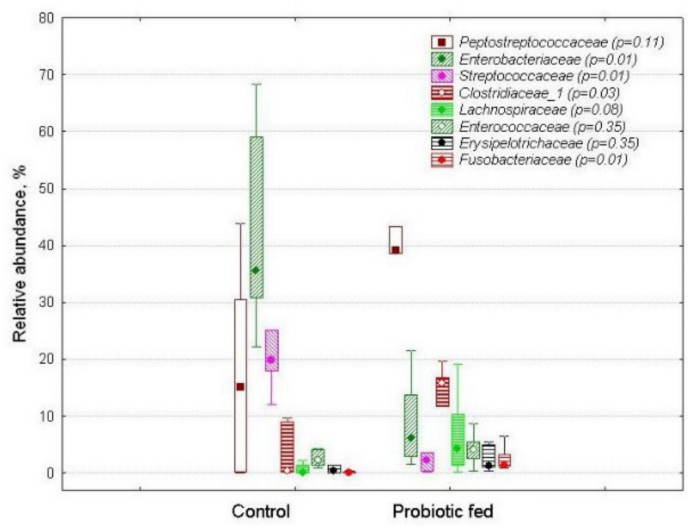

(d)

Figure 2. Relative abundance of taxon-specific sequences in fecal bacterial assemblages of ducks of the control and probioticfed groups: (a) phylum, (b) class, (c) order and (d) family levels. The markers show median, boxes show 25-75\% percentiles, while the lines indicate fluctuation ranges. The $p$-values as estimated for each taxon by Mann-Whitney test are shown in brackets.

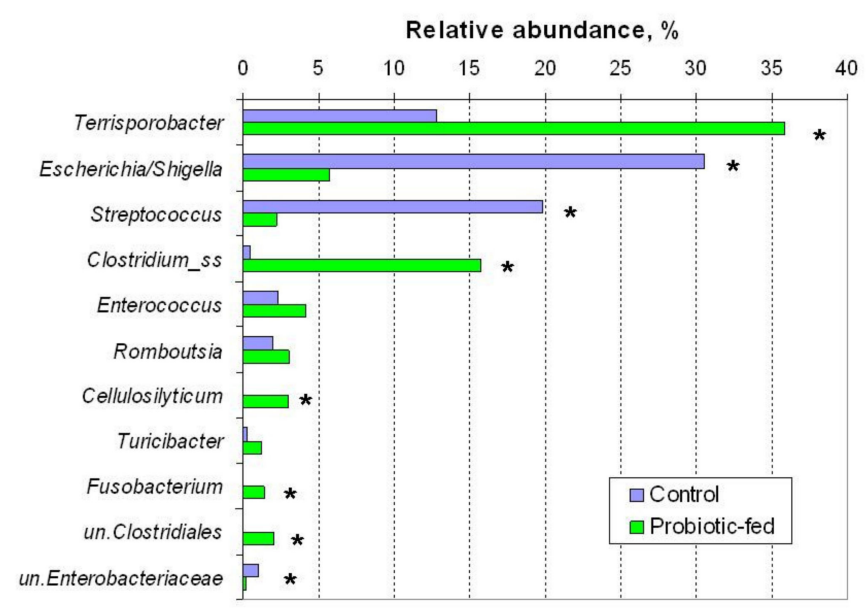

Figure 3. Relative abundance of genera in fecal bacterial assemblages of ducks of the control and probiotic-fed groups. Symbol * at the right of the columns denotes statistically significant difference between the groups (Mann-Whitney test, $p \leq 0.05$ ). "un." stands for unclassified. 
Of the total OTU number detected in the studied samples, only 13 OTUs, or $2 \%$, were dominants, i.e., contributed $\geq 1 \%$ to the total number of sequences (Table 1 ). The number of dominant OTUs per sample varied from three to nine in the control group, with just two OTUs being common for all samples (Escherichia/Shigella sp. and Streptococcus sp.). In the probiotic-fed group the number of dominant OTUs varied from 5 to 17 per sample, with three OTUs being common for all samples (Escherichia/Shigella sp., Terrisporobacter sp. and Romboutsia sedimentorum). Thus only one OTU, namely Escherichia/Shigella sp., was common for all studied samples. Its relative abundance varied from 30 to $68 \%$ in samples of the control group, and from 6 to $20 \%$ in samples of the probiotic-fed group.

\subsection{OTUs' Relative Abundance in Duck Fecal Bacterial Assemblages}

The relative abundance of some OTUs found in the bacterial assemblages of ducks is shown in Table 2. As mentioned above, the ultimate dominant in the control group was Escherichia/Shigella sp. The second major dominant OTU in the control group was Streptococcus sp. In fecal assemblages of the probiotic-fed group the abundance of this bacterium was almost 10 times lower.

Table 2. Relative abundance (\%) of bacterial OTUs, dominant in the fecal assemblages of ducks of the control and/or probiotic-fed groups.

\begin{tabular}{|c|c|c|c|c|}
\hline & OTU & Control Group & Probiotic-Fed Group & $p$-Value \\
\hline 1 & $\begin{array}{c}\text { Escherichia/ Shigella sp. } \\
1\end{array}$ & 30.6 & 5.7 & 0.012 \\
\hline 2 & Terrisporobacter sp. & 12.9 & 36.4 & 0.037 \\
\hline 3 & Streptococcus sp. & 20.0 & 2.2 & 0.012 \\
\hline 6 & Enterococcus cecorum & 1.2 & 3.8 & 0.210 \\
\hline 7 & unc. Clostridiaceae_1 ${ }^{2}$ & 0.2 & 3.7 & 0.012 \\
\hline 8 & Clostridium_ss ${ }^{3} s p$. & 0.3 & 1.5 & 0.295 \\
\hline 10 & Cellulosilyticum sp. & 0.1 & 1.3 & 0.094 \\
\hline 11 & Turicibacter sanguinis & 0.3 & 1.2 & 0.403 \\
\hline 12 & unc. Clostridiales & 0.01 & 1.9 & 0.094 \\
\hline 13 & Clostridium_ss ${ }^{3} s p$. & 0.04 & 1.04 & 0.210 \\
\hline 14 & Fusobacterium sp. & 0.11 & 1.41 & 0.012 \\
\hline 15 & $\begin{array}{l}\text { Cellulosilyticum } \\
\text { lentocellum }\end{array}$ & 0.04 & 1.48 & 0.037 \\
\hline 19 & $\begin{array}{l}\text { Romboutsia } \\
\text { sedimentorum }\end{array}$ & 2.0 & 3.2 & 0.403 \\
\hline
\end{tabular}

${ }_{1}$ The lines with statistically significant $(p \leq 0.05)$ difference are highlighted in bold; ${ }^{2}$ "unc." stands for unclassified 3 "ss" stands for sensu stricto.

Overall, 70 OTUs were found to have differential relative abundance $(p \leq 0.05)$ in fecal microbiota of the studied groups. Most of these OTUs were minor or rare members, contributing much less than $1 \%$ into the total number of sequence reads.

Four dominant OTU were found to have increased $(p \leq 0.05)$ abundance in fecal bacteriobiomes of the probiotic-fed group. Terrisporobacter sp. sequences were almost three times more abundant in the probiotic-fed group, comprising one third of the entire bacteriobiome. A Fusobacterium sp. was also found increased in the probiotic-fed group (Table 2).

\subsection{Biodiversity Indices of the Duck Fecal Bacterial Assemblages}

Biodiversity indices serve to compact information about communities, assemblages, guilds, etc. of living organisms; thus, the indices are useful for comparing large arrays of metagenomic data. Therefore, for each studied sample, i.e., an array with the number of sequence reads for each OTU, we calculated $\alpha$-biodiversity indices (Table 3 ). 
Table 3. Alpha-biodiversity indices (median) of fecal bacterial assemblages of ducks of the control and probiotic-fed group.

\begin{tabular}{cccc}
\hline Index & Control Group & Probiotic-Fed Group & $p$-Value \\
\hline Total number of & 208 & 114 & 0.095 \\
identified OTUs & 0.31 & 0.17 & 0.222 \\
Dominance (D) & 0.69 & 0.83 & 0.222 \\
Simpson (1-D) & 1.92 & 2.49 & 0.151 \\
Shannon & 0.02 & 0.06 & 0.032 \\
Evenness & 1.91 & 2.49 & 0.151 \\
Brillouin $_{\text {Menhinick }}^{1}$ & 0.85 & 0.51 & 0.032 \\
Margalef & 19 & 9 & 0.095 \\
Equitability & 0.33 & 0.49 & 0.095 \\
Fisher-alpha & 27 & 13 & 0.095 \\
Berger-Parker & 0.46 & 0.36 & 0.841 \\
Chao-1 & 246 & 127 & 0.095 \\
\hline
\end{tabular}

${ }^{1}$ The lines with statistically significant $(p \leq 0.05)$ difference are highlighted in bold.

The probiotic-fed group showed a tendency for decreased OTU richness, as indicated by the number of OTUs, Chao-1, Fisher's alpha, Margalef and Menchinik indices, and increased evenness, with Shannon and Brilluin indices, on the contrary, tending to increase in the probiotic-fed group.

\subsection{Production Performance of Ducks}

The data on production characteristics for the entire groups, i.e., consisting of 16 birds each, were normally distributed: ANOVA showed that probiotic supplementation accounted for $43 \%$ of the bird body mass variance at day 60 and for $30 \%$ of the growth rate variance. Thus due to the beneficial effect of probiotic-enriched feed ducks' production characteristics improved, as the probiotic-fed ducks demonstrated (Table 4) higher both daily mass increase rate (by $4.0 \mathrm{~g} / \mathrm{bird}$ ) and total body mass at the end of the feeding (by $235 \mathrm{~g} /$ bird).

Table 4. Production characteristics of ducks fed with conventional (control) and probiotic-supplemented feed (probioticfed group).

\begin{tabular}{|c|c|c|c|}
\hline Characteristic & Control Group $(n=16)^{2}$ & Probiotic-Fed Group $(n=16)$ & $p$-Value ${ }^{1}$ \\
\hline Living mass of a 1-day-old duck, g/bird & $57.8 \pm 5.8^{2}$ & $57.9 \pm 6.3$ & 0.931 \\
\hline Living mass of a 60-day-old duck, g/bird & $2772 \pm 222$ & $3007 \pm 141$ & 0.001 \\
\hline Average daily gain, g/bird per day & $45.2 \pm 3.7$ & $49.2 \pm 2.3$ & 0.001 \\
\hline Feed intake, $\mathrm{kg} / \mathrm{kg}$ bird mass & 3.35 & 2.85 & \\
\hline
\end{tabular}

${ }^{1}$ The lines with statistically significant $(p \leq 0.05)$ difference are highlighted in bold. ${ }^{2}$ Performance was assessed for a bigger sets of birds than the fecal microbiome.

Supplementing conventional duck feed with probiotic resulted in $0.5 \mathrm{~kg}$ less consumption per $1 \mathrm{~kg}$ of duck living mass. The ducks in the control group consumed on average $0.72 \mathrm{~kg}$ more feed, as compared to the probiotic-fed ducks.

\section{Discussion}

The finding that two bacterial phyla, namely Firmicutes and Proteobacteria, prevailed in the ducks' feces agrees with the results obtained in other studies: for instance, the representatives of Firmicutes, Proteobacteria and Bacteroidetes were reported to account for at least $90 \%$ of bacteriobiomes in duck's ileum and cecum [28-31]. As for the rectum (as in our study), recently Firmicutes and Proteobacteria were found to account for $75 \%$ of the Muscovy ducks' rectum bacteriobiome [32], with Proteobacteria abundance being twice lower as in the control group in our study $(15 \%$ vs. $30 \%)$.The difference may be attributed 
to the difference in duck species and sex, as well as other factors; this is an area that is still poorly investigated.

The fact that we did not explicitly detect B. subtilis and B. licheniforms, the major components in the probiotic preparation, may be due to the relatively short V3-V4 amplicon sequences, not allowing discrimination between closely related species [33]. Our result that the probiotic bacteria consumed by the ducks with their feed did not reside in the gut complies with the fact that Bacillus representatives are not common for the gut microbiota of poultry $[31,34]$.

The occurrence of an Escherichia/Shigella bacterium in the probiotic-fed group was more than five times lower. The genus represents important pathogens of humans and animals [35], therefore the change was most likely beneficial for birds' health and welfare. Among the Streptococcus genus some serious pathogens for humans and animals were reported before: for example, the ones capable of causing meningitis in ducks [36]. Thus it seems that Streptococcus sp. in our study was not a beneficial bacterium, so decrease in the probiotic-fed ducks might have contributed to their enhanced production performance. The drastically decreased abundance of these two harmful bacteria, i.e., Escherichia/Shigella sp. and Streptococcus sp., in the probiotic-fed group confirms the antagonistic and hence beneficial impact of the Bacillus-based probiotic on the major opportunistic pathogens of the fecal microbiota of ducks. It should be noted that the ducks in this study harboring abundant Escherichia/Shigella and Streptococcus were apparently healthy, which means that even high abundance of a potential pathogen's sequence reads in a bacteriobiome is not be immediately manifested as an actual instance of a disease.

Although some authors claim that Riemerella anatipestifer is one of the most common bacterial pathogens of ducks [32], in our study none of the assigned OTUs were classified into Riemerella.

The finding that most of the differentially abundant OTUs in fecal bacterial assemblages of the conventionally and probiotic-fed groups were minor or rare members suggests that low-abundant OTUs may be important for the host adjustments to shifts in environmental conditions. Such OTUs in the gut microbiome may have systemic interactions with potentially important consequences for the microbial performance within a host organism.

There is evidence about the pathogenicity of the Terrisporobacter genus for humans [37], but for animals and poultry we could not find such information. Some Terrisporobacter genus representatives are known as chemoorganotrophs, while others are chemolithoautotrophs, or acetogenic bacteria $[38,39]$, capable of decomposing plant material in anaerobic conditions. Thus this bacterium is beneficial for host functioning, and its increased abundance in the probiotic-fed ducks' feces also confirms the positive effect of the Bacillus-based probiotic on the fecal microbiota of ducks.

Although recently a Fusobacterium sp. was reported to be associated with decreased production of hens, thus likely being an opportunistic pathogen [40], Fusobacteria phylum representatives are common and often dominant members of the gut microbiota of wild ducks and geese [41]. In view of the latter the increased relative abundance of the bacterium in the probiotic-fed group can also be considered promoting intestinal health of the ducks. As for Cellulosilyticum lentocellum, another bacterium with increased abundance in the feces of the probiotic-fed ducks, it is known as a slow cellulose-degrader and member of the healthy animal fecal bacteriobiome [42]. Increased presence of an unclassified Clostridiaceae_1 OTU, important anaerobic degraders of plant polymers [43], in the fecal bacteriobiome of probiotic-fed ducks, can be considered beneficial and hence might have contributed to higher production performance of the ducks. Overall, increased abundance of Clostridiales representatives in probiotic-fed ducks corroborates the use of these bacteria for novel probiotic formulations: recently some of the latter were shown to exert beneficial influence on Peking duck performance [44].

It should be noted that the available information about the influence of probioticenriched feed on ducks' gut microbiota is inconclusive, as both beneficial [28] and neutral effects were reported earlier [45]. One of the reasons for such a discrepancy may be because 
two independent groups of birds, with and without probiotic supplementation, are usually compared: implementing the repeated measures design, i.e., sampling the same member of a group before and after the probiotic treatment, is more difficult in practice even in case of feces. Other reasons may be associated with regional/country differences between the studied duck groups such as lifespan, feed and its supplementation, medication, raising conditions, genetics $[28,30]$, etc.

Compared with the $\alpha$-biodiversity indices for the gut microbiota of ducks reported earlier [30], in our study Shannon and Chao-1 indices were lower. The dominance indices were found to show tendency to be lower in probiotic-fed group, while equitability tended to be higher. Therefore, overall $\alpha$-diversity seemed to be increasing in the probiotic-fed group, which is generally regarded as positive.

Our finding that probiotic supplementation decreased feed consumption per unit of living mass of the ducks indirectly corroborates the results about increased abundance of beneficial, particularly plant material fermenting, bacteria, which most likely translated into more efficient transformation of nutrients in the gut and consequent more efficient utilization of nutrients by host organisms, i.e., ducks.

The found beneficial effect of probiotic-enriched feed on ducks' production characteristics agrees with the improved production performance of probiotic-fed Pitalah ducks [46]. The Pekin ducks' productivity performance in our study corroborates the beneficial influence of Bacillus-based supplementation on egg quality and biochemical properties of blood of Shaoxing ducks [47], and on gut microbiota established with lysine-yielding Bacillus subtilis on a locally domesticated Chinese duck breed [48]. Enhanced Pekin ducks' production, associated with beneficial changes in ducks' gut microbiota due to Bacillus-based probiotic supplementation, is also in line with improved growth performance shown by the Cherry Valley ducks [13]. Therefore, the studied Bacillus-based probiotic formulation a promising basis for further improvement [6] and use.

Finally, we want to stress that it is difficult to compare studies on duck intestinal micrtobiome diversity due to substantive differences in methodology, beginning from the studied groups (species, breed, age, raising conditions, site of sample collection in the gut, etc.) and all the way to amplification (primers), sequencing (platforms) and bioinformatic tools (software and databases). Therefore, there is an urgent need for a comprehensive meta-analysis of the duck gut microbiome data, hopefully resulting in recommendations for a more standardized research approach.

We also want to emphasize, albeit truistically, that case-control design, often used to infer the medication/supplementation-associated effects in humans and animals, prevents following directly, i.e., in one and the same individual, the dynamics of the properties of interest, i.e., bacteriobiome diversity as in our study. Therefore, repeated measures' design should be implemented if and when possible and feasible, despite the objective difficulties of doing so in studies with animals. Such a design helps to move closer to the causeeffect mechanisms of microbiome shifts, rather than be confined to association/correlation relations, as most of the microbiome studies do.

\section{Conclusions}

Our study aimed at comparing the structure and composition of fecal microbiota, as determined using $16 \mathrm{~S}$ rRNA gene amplicon sequencing, in ducks receiving conventional and Bacillus-based probiotic supplemented feed. This is the first profile of gut bacteriobiome of domestic ducks in Russia and as such can be used as a regional reference in further research as well as a tiny contribution for constructing the global pattern. Duck fecal bacteriobiome was found to be drastically dominated by just two phyla (Firmicutes and Proteobacteria), represented by three classes (Clostridia, Bacilli and Gammaproteobacteria). Escherichia/Shigella sp. turned out to be the major and sole common dominant in all samples. Fecal bacteriobiome of probiotic-fed ducks differed from the conventionally fed control in the relative abundance of some dominant OTUs, mainly the pathogenic ones (Escherichia/Shigella sp., Streptococcus sp.). A number of minor and rare members of bacterial 
assemblages ( $12 \%$ of the total number of OTUs) also displayed differential abundance; however, it was difficult to infer their physiological and/or pathogenic significance. The Bacillus bacteria, contained in the probiotic preparation used in the study, could not survive in the gut and were eliminated. Supplementation of the conventional feed with Bacillusbased probiotic resulted in pronounced shifts towards the more beneficial gut microbiota of ducks. The increased bacteriobiome $\alpha$-diversity in the probiotic-fed group enhance gut microbiota and hence ducks' resilience towards adverse environmental effects. The bacterial OTUs, found to be the significantly related to the probiotic supplementation, provide a framework for further research on bacteria functioning and interactions within gut microbiota in order to improve birds' health and, as a consequence, both industrial and small farm poultry production. The studied Bacillus-based probiotic is promising for the development of improved formulations for specifically targeted interventions to modify gut microbiota of ducks. Such formulations can be effective alternatives for growthpromoting antibiotics, but there is still a great need to understand the role of poultry gut microbiota in the prophylaxis, growth and health promoting mechanisms.

Author Contributions: Conceptualization, V.I.P. and N.S.Z.; methodology, V.I.P.; software, M.R.K.; validation, T.Y.A., N.B.N. and A.V.K.; formal analysis, N.B.N.; investigation, A.V.K.; resources, V.I.P.; data curation, N.B.N.; writing—original draft preparation, N.B.N.; writing-review and editing, N.A.L., M.R.K. and V.I.P.; visualization, T.Y.A.; supervision, M.R.K.; project administration, V.I.P.; funding acquisition, V.I.P. All authors have read and agreed to the published version of the manuscript.

Funding: This research was funded by the MINISTRY OF SCIENCE AND HIGHER EDUCATION OF THE RUSSIAN FEDERATION (project number 121031300042-1).

Institutional Review Board Statement: The study was conducted according to the guidelines of the Declaration of Helsinki, and approved by the Institutional Review Board of STOLYPIN OMSK STATE AGRARIAN UNIVERSITY (protocol code 23/11 23 August 2018).

Informed Consent Statement: All experimental procedures involving ducks met the guidelines approved by the in-stitutional animal care and use committee and were performed in accordance with the Russian National Law concerning the care of animals for research purposes, as well as in compliance with the European Commission Directive 2010/63/EU on the protection of animals used for scientific purposes.

Data Availability Statement: The read data reported in this study were submitted to the GenBank under the study accession PRJNA523560.

Acknowledgments: In this section, you can acknowledge any support given which is not covered by the author contribution or funding sections. This may include administrative and technical support, or donations in kind (e.g., materials used for experiments).

Conflicts of Interest: The authors declare no conflict of interest. The funders had no role in the design of the study; in the collection, analyses, or interpretation of data; in the writing of the manuscript, or in the decision to publish the results.

\section{References}

1. FAOSTAT. 2021. Available online: http://www.fao.org/faostat/en/\#data/QA (accessed on 20 April 2021).

2. Oviedo-Rondón, E.O. Holistic view of intestinal health in poultry. Anim. Feed Sci. Technol. 2019, 250, 1-8. [CrossRef]

3. Patterson, J.A.; Burkholder, K.M. Application of prebiotics and probiotics in poultry production. Poult. Sci. 2003, 82, 627-631. [CrossRef] [PubMed]

4. Sorokulova, I.B. A comparative study of the biological properties of Biosporin and other commercial Bacillus-based preparations. Mikrobiol. Zhournal 1997, 59, 43-49. (In Russian)

5. Mingmongkolchai, S.; Panbangred, W. Bacillus probiotics: An alternative to antibiotics for livestock production. J. Appl. Microbiol. 2018, 124, 1334-1346. [CrossRef]

6. Kogut, M.H. The effect of microbiome modulation on the intestinal health of poultry. Anim. Feed Sci. Technol. 2019, 250, 32-40. [CrossRef] 
7. Franciosini, M.P.; Costarelli, S.; Cobellis, G.; Trabalza-Marinucci, M. Effects of dietary Lactobacillus acidophilus and Bacillus subtilis on laying performance, egg quality, blood biochemistry and immune response of organic laying hens. J. Anim. Physiol. Anim. Nutr. 2016, 100, 977-987. [CrossRef]

8. Zamanizadeh, A.; Mirakzehi, M.T.; Agah, M.J.; Saleh, H.; Baranzehi, T. A comparison of two probiotics Aspergillus oryzae and Saccharomyces cerevisiae on productive performance, egg quality, small intestinal morphology, and gene expression in laying Japanese quail. Ital. J. Anim. Sci. 2021, 20, 232-242. [CrossRef]

9. Wang, H.; Ha, B.D.; Kim, I.H. Effects of probiotics complex supplementation in low nutrient density diet on growth performance, nutrient digestibility, faecal microbial, and faecal noxious gas emission in growing pigs. Ital. J. Anim. Sci. 2020, 20, 163-170. [CrossRef]

10. Liu, X.; Liu, W.; Deng, Y.; He, C.; Xiao, B.; Guo, S.; Zhou, X.; Tang, S.; Qu, X. Use of encapsulated Bacillus subtilis and essential oils to improve antioxidant and immune status of blood and production and hatching performance of laying hens. Ital. J. Anim. Sci. 2020, 19, 1583-1591. [CrossRef]

11. Park, I.; Lee, Y.; Goo, D.; Zimmerman, N.P.; Smith, A.H.; Rehberger, T.; Lillehoj, H.S. The effects of dietary Bacillus subtilis supplementation, as an alternative to antibiotics, on growth performance, intestinal immunity, and epithelial barrier integrity in broiler chickens infected with Eimeria maxima. Poult. Sci. 2020, 99, 725-733. [CrossRef]

12. Liu, X.; Peng, C.; Qu, X.; Guo, S.; Chen, J.F.; He, C.; Zhou, X.; Zhu, S. Effects of Bacillus subtilis C-3102 on production, hatching performance, egg quality, serum antioxidant capacity and immune response of laying breeders. J. Anim. Physiol. Anim. Nutr. 2019, 103, 182-190. [CrossRef] [PubMed]

13. Guo, M.; Hao, G.; Wang, B.; Li, N.; Li, R.; Wei, L.; Chai, T. Dietary Administration of Bacillus subtilis Enhances Growth Performance, Immune Response and Disease Resistance in Cherry Valley Ducks. Front. Microbiol. 2016, 7, 1975. [CrossRef] [PubMed]

14. Khattab, A.; El Basuini, M.; El-Ratel, I.T.; Fouda, S.F. Dietary probiotics as a strategy for improving growth performance, intestinal efficacy, immunity, and antioxidant capacity of white Pekin ducks fed with different levels of CP. Poult. Sci. 2021, 100, 100898. [CrossRef] [PubMed]

15. Directive 2010/63/EU of the European Parliament and of the Council of 22 September 2010 on the Protection of Animals Used for Scientific Purposes. Available online: https:/ / data.europa.eu/eli/dir/2010/63/oj (accessed on 27 April 2021).

16. Probiotic Plus LLC. Available online: https:/ /www.probiotic-plus.ru (accessed on 27 April 2021). (in Russian).

17. Federal Service for Proprietary Rights. Patent RU 2,437,563C1, 27 December 2011.

18. QIAGEN. Quick-Start Protocol. DNeasy PowerSoil Kit. 2016. Available online: https://www.qiagen.com/au/resources/ resourcedetail?id=91cf8513-a8ec-4f45-921e-8938c3a5490c\&lang=en (accessed on 27 April 2021).

19. Fadrosh, D.W.; Ma, B.; Gajer, P.; Gajer, P.; Sengamalay, N.; Ott, S.; Brotman, R.M.; Ravel, J. An improved dual-indexing approach for multiplexed 16S rRNA gene sequencing on the Illumina MiSeq platform. Microbiome 2014, 2, 6. [CrossRef] [PubMed]

20. Igolkina, A.A.; Grekhov, G.A.; Pershina, E.V.; Samosorova, G.G.; Leunova, V.M.; Semenov, A.N.; Baturina, O.A.; Kabilov, M.R.; Andronov, E.E. Identifying components of mixed and contaminated soil samples by detecting specific signatures of control $16 \mathrm{~S}$ rRNA libraries. Ecol. Ind. 2018, 94, 446-453. [CrossRef]

21. Edgar, R.C. UPARSE: Highly accurate OTU sequences from microbial amplicon reads. Nat. Methods 2013, 10, 996-998. [CrossRef]

22. Edgar, R.C. UNOISE2: Improved error-correction for Illumina 16S and ITS amplicon reads. bioRxiv 2016. [CrossRef]

23. Wang, Q.; Garrity, G.M.; Tiedje, J.M.; Cole, J.R. Naïve Bayesian Classifier for Rapid Assignment of rRNA Sequences into the New Bacterial Taxonomy. Appl. Environ. Microbiol. 2007, 73, 5261-5267. [CrossRef]

24. Fauth, E.; Bernardo, J.; Camara, M.; Resetarits, W.J.; Van Buskirk, J.A.; McCollum, S. Simplifying the Jargon of Community Ecology: A Conceptual Approach. Am. Nat. 1996, 147, 282-286. [CrossRef]

25. Hsieh, T.C.; Ma, K.H.; Chao, A. iNEXT: An R package for rarefaction and extrapolation of species diversity (Hill numbers). Methods Ecol. Evol. 2016, 7, 1451-1456. [CrossRef]

26. Hammer, Ø.; Harper, D.A.T.; Ryan, P.D. PAST: Paleontological Statistics Software Package for Education and Data Analysis. Palaeontol. Electron. 2001, 4, 1-9.

27. Hughes, J.B.; Hellmann, J.J. The Application of Rarefaction Techniques to Molecular Inventories of Microbial Diversity. Methods Enzymol. 2005, 397, 292-308. [CrossRef]

28. Vasaï, F.; Ricaud, K.B.; Cauquil, L.; Daniel, P.; Peillod, C.; Gontier, K.; Tizaoui, A.; Bouchez, O.; Combes, S.; Davail, S. Lactobacillus sakei modulates mule duck microbiota in ileum and ceca during overfeeding. Poult. Sci. 2014, 93, 916-925. [CrossRef] [PubMed]

29. Best, A.A.; Porter, A.L.; Fraley, S.M.; Fraley, G.S. Characterization of Gut Microbiome Dynamics in Developing Pekin Ducks and Impact of Management System. Front. Microbiol. 2017, 4, 2125. [CrossRef] [PubMed]

30. Wang, S.; Chen, L.; He, M.; Shen, J.; Li, G.; Tao, Z.; Wu, R.; Lu, L. Different rearing conditions alter gut microbiota composition and host physiology in Shaoxing ducks. Sci. Rep. 2018, 8, 7387. [CrossRef] [PubMed]

31. Chen, X.; Zheng, M.; Lin, F.; Cheng, X.; Xiao, S.; Chen, S.; Chen, S. Impacts of novel duck reovirus infection on the composition of intestinal microbiota of Muscovy ducklings. Microb. Pathog. 2019, 137, 103764. [CrossRef] [PubMed]

32. Yang, H.; Lyu, W.; Lu, L.; Shi, X.; Li, N.; Wang, W.; Xiao, Y. Biogeography of microbiome and short-chain fatty acids in the gastrointestinal tract of duck. Poult. Sci. 2020, 99, 4016-4027. [CrossRef] [PubMed]

33. Jensen, E.A.; Berryman, D.E.; Murphy, E.R.; Carroll, R.K.; Busken, J.; List, E.O.; Broach, W.H. Heterogeneity spacers in 16S rDNA primers improve analysis of mouse gut microbiomes via greater nucleotide diversity. Biotechniques 2019, 67, 55-62. [CrossRef] 
34. Pandit, R.J.; Hinsu, A.T.; Patel, N.V.; Koringa, P.G.; Jakhesara, S.J.; Thakkar, J.R.; Shah, T.M.; Limon, G.; Psifidi, A.; Guitian, J.; et al. Microbial diversity and community composition of caecal microbiota in commercial and indigenous Indian chickens determined using 16s rDNA amplicon sequencing. Microbiome 2018, 6, 115. [CrossRef]

35. Gaastra, W.; Kusters, J.G.; van Duijkeren, E.; Lipman, L.J.A. Escherichia fergusonii. Vet. Microbiol. 2014, 172, 7-12. [CrossRef]

36. Li, M.; Gu, C.; Zhang, W.; Li, S.; Liu, J.; Qin, C.; Su, J.; Cheng, G.; Hu, X. Isolation and characterization of Streptococcus gallolyticus subsp. pasteurianus causing meningitis in ducks. Vet. Microbiol. 2013, 162, 93036. [CrossRef]

37. Cheng, M.P.; Domingo, M.C.; Lévesque, S.; Yansouni, C.P. A case report of a deep surgical site infection with Terrisporobacter glycolicus/T. Mayombei and review of the literature. BMC Infect. Dis. 2016, 29, 529. [CrossRef]

38. Müller, V.; Frerichs, J. Acetogenic Bacteria; John Wiley \& Sons Ltd.: Hoboken, NJ, USA, 2013. [CrossRef]

39. Groher, A.; Weuster-Botz, D. General medium for the autotrophic cultivation of acetogens. Bioprocess Biosyst. Eng. 2016, $39,1645$. [CrossRef] [PubMed]

40. Kollarcikova, M.; Kubasova, T.; Karasova, D.; Crhanova, M.; Cejkova, D.; Sisak, F.; Rychlik, I. Use of 16S rRNA gene sequencing for prediction of new opportunistic pathogens in chicken ileal and cecal microbiota. Poult. Sci. 2019, 98, 2347-2353. [CrossRef]

41. Wang, W.; Zheng, S.; Li, L.; Yang, Y.; Liu, Y.; Wang, A.; Sharshov, K.; Li, Y. Comparative metagenomics of the gut microbiota in wild greylag geese (Anser anser) and ruddy shelducks (Tadorna ferruginea). MicrobiologyOpen 2019, 8, e00725. [CrossRef]

42. Miller, D.A.; Suen, G.; Bruce, D.; Copeland, A.; Cheng, J.F.; Detter, C.; Goodwin, L.A.; Han, C.S.; Hauser, L.J.; Land, M.L.; et al. Complete genome sequence of the cellulose-degrading bacterium Cellulosilyticum lentocellum. J. Bacteriol. 2011, 193, $2357-2358$. [CrossRef]

43. Wachemo, A.C.; Tong, H.Y.; Hairong, Z.X.; Korai, R.M.; Li, X. Continuous dynamics in anaerobic reactor during bioconversion of rice straw: Rate of substance utilization biomethane production and changes in microbial community structure. Sci. Total Environ. 2019, 687, 1274-1284. [CrossRef] [PubMed]

44. Liu, Y.; Jia, Y.; Liu, C.; Ding, L.; Xia, Z. RNA-Seq transcriptome analysis of breast muscle in Pekin ducks supplemented with the dietary probiotic Clostridium butyricum. BMC Genom. 2018, 28, 844. [CrossRef] [PubMed]

45. Even, M.; Davail, S.; Rey, M.; Tavernier, A.; Houssier, M.; Bernadet, M.D.; Gontier, K.; Pascal, G.; Ricaud, K. Probiotics Strains Modulate Gut Microbiota and Lipid Metabolism in Mule Ducks. Open Microbiol. J. 2018, 12, 71-93. [CrossRef] [PubMed]

46. Wizna, Z.; Abbas, M.H.; Mahata, M.E.; Fauzano, R. Effect of Bacillus amyloliquefaciens as a Probiotic on Growth Performance Parameters of Pitalah Ducks. Int. J. Poult. Sci. 2017, 16, 147-153. [CrossRef]

47. Li, W.F.; Rajput, I.R.; Xu, X.; Li, Y.L.; Lei, J.; Huang, Q.; Wang, M.Q. Effects of Probiotic (Bacillus subtilis) on Laying Performance, Blood Biochemical Properties and Intestinal Microflora of Shaoxing Ducks. Int. J. Poult. Sci. 2011, 10, 583-589. [CrossRef]

48. Xing, Y.; Wang, S.; Fan, J.; Oso, A.O.; Kim, S.W.; Xiao, D.; Yang, T.; Liu, G.; Jiang, G.; Li, Z.; et al. Effects of dietary supplementation with lysine-yielding Bacillus subtilis on gut morphology, cecal microflora, and intestinal immune response of Linwu ducks. J. Anim. Sci. 2015, 93, 3449-3457. [CrossRef] [PubMed] 